\title{
Introduction to A Research Agenda for Environmental Management -Through transdisciplinary, social science-rich environmental governance research
}

\author{
Kathleen E. Halvorsen, Jessie L. Knowlton, Chelsea Schelly, \\ Robert M. Handler and Erin C. Pischke
}

\section{Introduction}

Forty-seven years after the first Earth Day, environmental management problems remain some of humanity's greatest unsolved challenges. Climate change, resource scarcity, air and water pollution, and biodiversity losses continue and are, in some cases, worsening over time (Berkes et al., 2003). Developing the capacity to successfully understand these problems and their solutions therefore remains an important research agenda item.

Unfortunately, environmental management research problems have more commonly been defined as predominantly natural science problems to be studied by biologists, ecologists and chemists or engineering science problems to be solved with technology. These approaches have failed to help us solve many of these critical problems. Increasingly, foundation, policy making and science funding organizations and agencies call for broader inclusion of social science in interdisciplinary (ID) and even transdisciplinary (TD) research approaches (Baerwald et al., 2016). Unfortunately, few individuals and organizations are proficient in developing and managing ID, much less TD, environmental management research teams (Halvorsen et al., 2016; Hadorn et al., 2008).

Based on experience working together and teaching on environmental management research, we believe that the best approach views environmental problems as "governance" issues. By governance, we mean issues around human relationships to the environment, including understanding the social dimensions of these problems as well as their technical components (engineered elements) and natural science elements (often embedded in the ecosystems with which humans are interacting; Vatn, 2016). Social and environmental systems interface through relationships that may simultaneously be policy-driven, technologically based and behaviorally grounded. Figure 1.1 illustrates this system including social, technological and environmental components (Vatn, 2016). As this figure shows, the nature of these relationships often has profound cultural, political, organizational, psychological, 


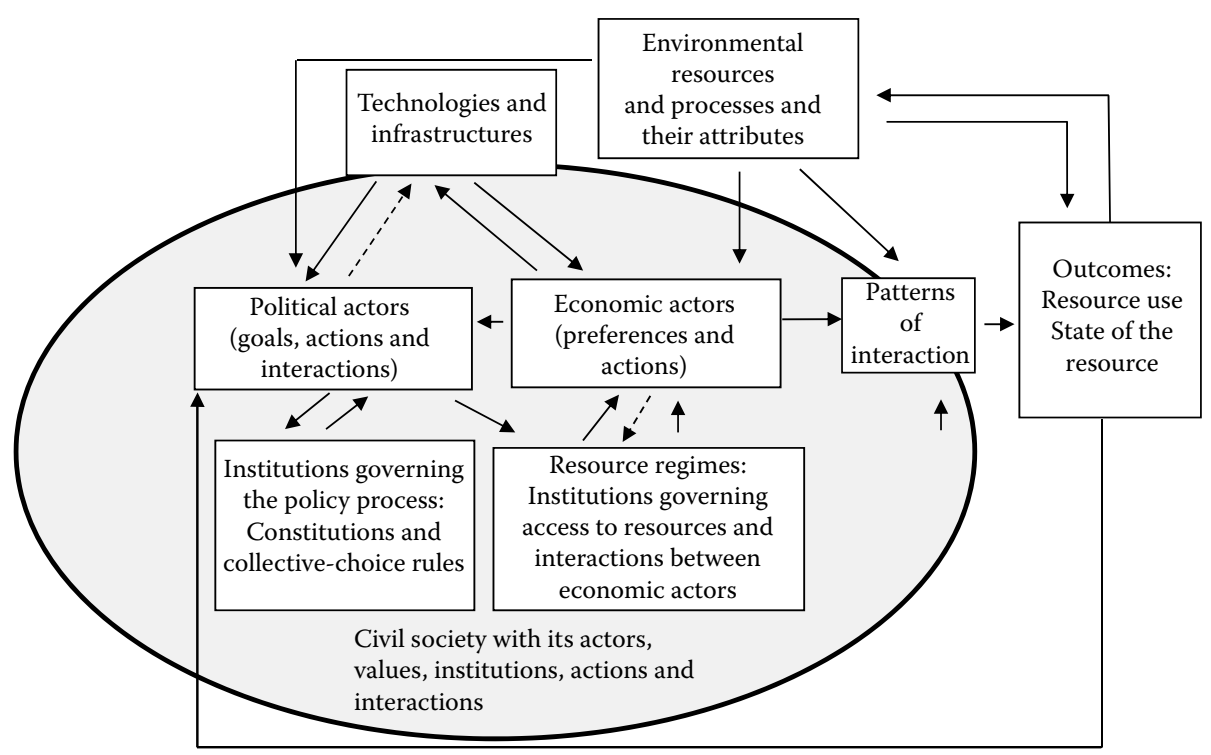

Note: From Vatn, 2016, used with permission.

Figure 1.1 The environmental governance system

historical, and spatial components - the provenance of various types of social science. As is discussed in more detail in Chapters Two and Three, understanding the fundamental basis for environmental management - the definition of the environmental problem and its solution - therefore demands the integration of social sciences with natural and/or engineering sciences.

However, as shown in Figure 1.1, approaching environmental management as environmental governance also brings us into a complex social system of groups and individuals who have defined the environmental problem, are potentially contributing to its causes, may support or oppose specific types of solutions, are affected by the problem and/or its solution(s), and will be involved in carrying out solutions (Vatn, 2016). This is the realm of diverse individuals and groups beyond science: that of industry, policy makers, non-governmental organizations, sovereign nations (tribes, cross-national contexts) and human community members.

Environmental management research that provides true understanding of problems and solutions therefore needs to include significant social science, integrated with natural and/or engineering sciences, combined with team members representing diverse types of groups. Successfully developing and managing such research teams is difficult. This research agenda book therefore focuses on three interrelated tasks as represented in the three main parts of the book: (a) establishing a rationale for a social science-centered TD approach to environmental management (Part I); (b) discussing the challenges associated with this approach 
as well as strategies for overcoming them (Part II); and (c) showcasing how these challenges can be overcome through the presentation of a series of case studies illustrating how this can and has been done by research teams studying different types of environmental management problems (Part III). This first chapter is an overall introduction to the primary concepts used throughout and to the book with upcoming sections detailing some of the definitions of terms, history leading to their development, and summarizing and synthesizing the main emphases of the chapters that follow.

\section{History of the development of transdisciplinarity}

The recognition of significant environmental problems arguably peaked in the 1960 s and 1970 s as post-World War II economic booms resulted in sharply increased air and water pollution (Kraft and Vig, 2015). Over time, scientists and governments developed new policies and professionals focused on solving these problems. The professionals tended to come from natural and engineering sciences, with, for example, the emergence of various types of ecology and the new field of environmental engineering. Much of this early environmentalism conceptualized humans as external to the biophysical worlds the field was trying to protect.

The field expanded and refined itself into the 1970s paralleling the emergence of Earth Day, the Stockholm Declaration and the development of the United Nations Environmental Program (UNEP) (Kraft and Vig, 2015). One outcome was the definition of the term "sustainability", a term that has come to be associated with many other fields, including sustainable development and manufacturing. Sustainability, defined as "development that meets the needs of the present without compromising the ability of future generations to meet their own needs" (Brundtland, 1987), was grounded in the concept of incorporating people into environmentalism equation, at least in terms of trying to satisfy human needs. This history is described in more detail in Chapter Two.

Meanwhile, traditional social science disciplines across the world began to develop new environmentally focused specialty areas from within traditional social science departments and also in natural resource and environmentally focused departments, including often cross-departmental environmental science and studies programs. Over time, environmental geography, anthropology and sociology joined environmental and natural resource social sciences as fully fledged specialty areas with graduate and undergraduate programs, professional societies, international conferences, and, increasingly, international environmental social science journals.

However, by and large social, natural and engineering scientists rarely collaborated across their fields. Two trends began to change this. One was the realization that, despite decades of trying, natural and engineering sciences alone were insufficient to solve many environmental problems. The second, interrelated with the first, was the emergence of funding opportunities from science agencies that called for ID 
proposals to carry out ID research and education, such as the late 1990s start of the US National Science Foundation Integrated Graduate Research and Education program and its Coupled Natural and Human Systems program that emerged from the coupled human-natural systems field (Baerwald et al., 2016).

\section{Defining interdisciplinary and transdisciplinary}

ID research links disparate disciplines to solve a common problem, by integrating the methods of each discipline and creating a shared language that leads to a more holistic approach to problem solving than a single discipline would allow (Buizer et al., 2015; Hickey and Nitschke, 2005). In the context of this book, an ID approach to solving environmental management problems refers to the required cooperation of social, natural and/or engineering scientists via integration of their various methods and development of a shared vision of both the problem and solution. TD research takes the ID approach one step further, and includes non-academics who are involved with the research topic or communities where fieldwork is taking place from the very beginning, including shared problem definition, methodology and final outcomes (Buizer et al., 2015; Hadorn et al., 2006).

Transdisciplinarity should be a reflexive, integrative, method-driven approach aiming at the solution of complex environmental management problems by differentiating and integrating knowledge from social, natural, engineering and societal bodies of knowledge (Lang et al., 2012). This definition highlights that TD research should focus on societally relevant problems, enable mutual learning processes among researchers from different disciplines and from outside academia, and create knowledge that is solution-oriented and transferable to both the scientific and societal practice (Lang et al., 2012).

\section{The structure of this book}

This book is designed to progress from fundamental concepts to strategies for overcoming common challenges to successful TD teamwork and ends by illustrating those strategies through a series of case studies of successful TD work. Part I focuses on introducing basic concepts with Chapter Two discussing underlying issues related to sustainability, governance and environmental management as well as raising key questions that justify the inclusion of strong social science capacities within TD teams. Chapter Three continues this discussion while focusing on the nuanced and difficult power dimensions associated with environmental governance questions. It is our intention that readers from diverse sectors and disciplines will find in this book a deeper understanding of how TD research can better develop environmental management solutions. We also hope that they will get a sense of the challenges of doing good TD work and strategies for overcoming them. Our case studies are designed to provide these readers with the stories of many TD research teams, how they developed, the challenges they faced and how 
they overcame them, and finally what taking a TD approach to studying a problem enabled the team to accomplish.

Part II focuses on discussing the challenges of successful TD teamwork in general, including, as presented in Chapter Four, strategies for overcoming them. Chapter Five discusses the challenges specific to including team members from other sectors, including non-governmental organizations. This is followed by Chapter Six with a discussion of the challenges specific to including public policy makers from all levels and branches of government. Chapter Seven delves into issues surrounding the involvement of general community members in research teams and defines a continuum of involvement that parallels that of TD teams generally. This section of the book is closed with a discussion of the challenges particular to TD teamwork across national boundaries.

Part III closes out the book with a set of case studies of research teams that span the continuum of research involvement presented in Chapter Seven. Some of the teams described in this section were deeply TD with individuals from non-science sectors included in the team from beginning to end. Others took a looser approach to TD, functioning more as ID research groups that used a more consultative approach to working with team members from other sectors. The research team described in Chapter Nine focused on understanding the causes of Lake Superior fish advisories and, through inclusion of community members in the definition of their research questions, discovered new dimensions to the issues under study.

Chapter 10 describes the challenges of a particularly large and international research team process showing how an ID group of scientists added other sectorial partners to understand tradeoffs related to renewable energy projects across the Americas. Chapter 11 delves more deeply into the community solar project described more briefly in Chapters Six and Seven to illustrate how researchers combined efforts with policy makers and community members to investigate development of local solar energy capacity. We move to a global scale in Chapter 12, illustrating the issues around TD research into diverse justice issues around conventional fossil fuel projects. Chapters 13 and 14 present the history of a TD research effort focused on understanding how household scale food-energy-water conservation can be encouraged (Chapter 13) and describing in more detail how the team took a TD approach to developing one research method - a role-playing game - to test research questions about effective behavioral interventions (Chapter 14). Finally, Chapter 15 closes out the book with an illustration of the inherently TD questions surrounding an increasingly pressing problem, supplying sufficient levels of potable water. 